\title{
Blocking Placental Class G Immunoglobulin Transfer Prevents NMDA Receptor Antibody Effects in Newborn Mice
}

Anna García-Serra, MSc, Marija Radosevic, PhD, José Ríos, MSc, Esther Aguilar, BS, Estibaliz Maudes, MSc, Jon Landa, MSc, Lidia Sabater, PhD, Eugenia Martinez-Hernandez, MD, PhD, Jesús Planagumà, PhD, and Josep Dalmau, MD, PhD

Neurol Neuroimmunol Neuroinflamm 2021;8:e1061. doi:10.1212/NXI.0000000000001061

\section{Abstract}

\section{Background and Objectives}

To determine in a mouse model whether neonatal $\mathrm{Fc}$ receptor $(\mathrm{FcRn})$ blockade prevents the placental transfer of class $\mathrm{G}$ immunoglobulin ( $\mathrm{IgG}$ ) derived from patients with anti-NMDA receptor (NMDAR) encephalitis and their pathogenic effects on the fetuses and offspring.

\section{Methods}

Pregnant C57BL/6J mice were administered via tail vein FcRn antibody (FcRn-ab) or saline solution 6 hours before administration of patients' or controls' IgG on days 14, 15, and 16 of gestation. Three experimental groups were established: mice receiving controls' IgG, patients' IgG, or patients' IgG along with pretreatment with FcRn-ab. Immunohistochemical staining, confocal microscopy, hippocampal long-term potentiation, and standardized developmental and behavioral tasks were used to assess the efficacy of treatment with FcRn-ab.

\section{Results}

In pregnant mice that received patients' IgG, treatment with FcRn-ab prevented the IgG from reaching the fetal brain, abrogating the decrease of NMDAR clusters and the reduction of cortical plate thickness that were observed in fetuses from untreated pregnant mice. Moreover, among the offspring of mothers that received patients' IgG, those whose mothers were treated with FcRn-ab did not develop the alterations that occurred in offspring of untreated mothers, including impairment in hippocampal plasticity, delay in innate reflexes, and visuospatial memory deficits.

\section{Discussion}

FcRn blockade prevents placental transfer of IgG from patients with anti-NMDAR encephalitis and abrogates the synaptic and neurodevelopmental alterations caused by patients' antibodies. This model has potential therapeutic implications for other antibody-mediated diseases of the CNS during pregnancy.
Correspondence

Dr. Dalmau

jdalmau@clinic.cat 


\section{Glossary}

$\mathbf{B B B}=$ blood-brain barrier; $\mathbf{C B A}=$ cell-based assay; DAPI = 6-diamidino-2-phenylindole dihydrochloride; $\mathbf{F c}=$ fragment, crystallizable of IgG antibodies; FcRn = neonatal Fc receptor; FcRn-ab = FcRn antibody; fEPSP = field excitatory postsynaptic potential; FNIT = fetal and neonatal immune thrombocytopenia; GEE = generalized estimated equation; HEK = human embryonic kidney; IgG = class G immunoglobulin; LTP = long-term potentiation; NMDAR = NMDA receptor; NOL = novel object location; PD = postnatal day; PSD95 = postsynaptic density protein 95; RT = room temperature.

Anti-NMDA receptor (NMDAR) encephalitis is a neuronal antibody-mediated disease that associates with prominent neuropsychiatric symptoms. ${ }^{1}$ Although the incidence of this disorder is unknown (estimated $\sim 1.5$ per million persons), it is considered the most frequent neuronal antibody-mediated encephalitis. ${ }^{2}$ Most clinical series show that $60 \%-80 \%$ of patients are women of childbearing age $\mathrm{e}^{3-5}$ who sometimes develop the encephalitis during pregnancy. ${ }^{6,7}$ In these cases, the severity of the maternal encephalitis (seizures, abnormal movements, coma, hypoventilation, or autonomic instability) 6,8 is an important risk factor for obstetric complications and potential brain damage of the fetuses and newborns. ${ }^{7}$

There is the additional concern that patient's NMDAR antibodies can reach the fetal brain and cause synaptic and neurodevelopmental alterations. These antibodies are pathogenic, as demonstrated in several experimental models. For instance, in cultured live neurons, patients' antibodies cause a robust reduction of NMDAR clusters along with a decrease of NMDARmediated currents ${ }^{9-11}$; and in a mouse model of cerebroventricular transfer of patients' CSF containing NMDAR antibodies, these alterations resulted in severe impairment of long-term plasticity, visuospatial memory deficits, depressive-like and psychotic-like behaviors. ${ }^{12-14}$

Animal studies examining placental transfer of NMDAR antibodies have reported potentially harmful effects in the offspring. Peritoneal injections of a patient-derived monoclonal antibody to pregnant mice caused high neonatal mortality and long-lasting deficits in the offspring. ${ }^{15}$ In another animal model, maternofetal transfer of class $G$ immunoglobulin ( $\operatorname{IgG}$ ) from patients with anti-NMDAR encephalitis resulted in NMDAR synaptic changes, delayed neurodevelopment, and behavioral deficits that progressively resolved after birth. ${ }^{16}$ These latest findings resemble the transient symptoms described in some newborns from patients with antiNMDAR encephalitis. ${ }^{7,17}$

The neonatal $F_{c}$ receptor $(\mathrm{FcRn})$ is responsible for the transport of IgG through the placenta and for extending serum IgG half-life after birth. ${ }^{18}$ Treatment with a monoclonal antibody able to block IgG binding to the FcRn ameliorated the severity of symptoms in experimental animal models of myasthenia gravis. ${ }^{19}$ In another study, administration of the same FcRn antibody (FcRn-ab) to immunized pregnant mice prevented pathogenic IgG-induced fetal and neonatal immune thrombocytopenia (FNIT) in the delivered neonates. ${ }^{20}$
A similar model using plasma from patients with myasthenia gravis and acetylcholine receptor antibodies prevented antibody-mediated systemic complications in fetuses (arthrogryposis multiplex congenita). ${ }^{21}$ Yet it is unknown whether this approach may work with an antibody-mediated disease of the CNS. Here, we examined the potential therapeutic use of FcRn blockade in a previously established mouse model of placental transfer of IgG from patients with antiNMDAR encephalitis.

\section{Methods}

\section{Human Serum Samples, IgG Purification, and Immunoabsorption}

IgG was isolated by ammonium sulfate precipitation from serum of 7 patients with anti-NMDAR encephalitis and serum of 7 healthy blood donors. All patients with anti-NMDAR encephalitis were women (median age 20 years, range 16-26 years) with classical anti-NMDAR encephalitis; none of the patients had teratoma, and in all instances, serum samples were obtained before treatment. The presence of NMDAR antibodies was determined with rat brain tissue immunohistochemistry and a cell-based assay (CBA) with human embryonic kidney (HEK) 293T cells expressing GluN1 and GluN2B receptor subunits, as reported. ${ }^{1}$ The absence of other brain-specific antibodies was established using previously reported experiments ${ }^{13,22}$ in which patients' NMDAR antibodies were immunoabsorbed, resulting in abrogation of patients' IgG effects in cultured neurons. ${ }^{23}$

\section{Animals}

Pregnant C57BL/6J mice (9 weeks old, 25-30 g, Charles River) were housed in cages of 5 until pregnancy day 16 (E16), at which time they were caged alone in previously reported room conditions. ${ }^{16}$ Representative offspring from every litter were separated by sex on postnatal day (PD) 21 , and kept in the same caging conditions until the indicated time points (i.e., PD 21 or 43). Overall, 21 pregnant female mice, 22 fetuses, and 91 pups were used for behavioral, electrophysiologic, morphological, and synaptic brain studies.

\section{Standard Protocol Approvals, Registrations, and Patient Consents}

Written informed consent was obtained from all patients; the study was approved by the local institutional review board at Hospital Clínic de Barcelona (registration number HCB/ 2018/0192). All procedures were approved by the local 
ethical committee of the University of Barcelona following European (2010/63/UE) and Spanish (RD 53/2013) regulations about the use and care of experimental animals.

\section{Infusion of Human IgG and FcRn-ab to Pregnant Mice}

Pooled IgG $(800 \mu \mathrm{g})$ from patients or controls was injected via tail vein to pregnant mice on days 14,15 , and 16 (E14, E15, and E16) of gestation (Figure 1), as previously reported. ${ }^{16}$ Mouse monoclonal FcRn-ab (3 mg/kg, GTX14550, GeneTex, Irvine, CA) or sterile saline solution was injected via tail vein on the same days of injection E14, E15, and E16, 6 hours before the human IgG administration to potentially block FcRn-mediated transplacental transfer of IgG. Three experimental groups were established: pregnant mice injected with controls' IgG, or injected with patients' IgG; or with patients' IgG and treated with FcRn-ab. These experiments were planned according to the window of time in which the $\mathrm{FcRn}$ is expressed in placental tissue, and the immature fetal blood-brain barrier (BBB) does not restrict the crossing of IgG (e.g., around gestational day 16, the BBB becomes significantly more restrictive to maternal antibody penetration into the fetal brain) as shown by us and others. ${ }^{16,24}$ FcRn-ab administration schedule was based on the findings from a passive transfer rat model of autoimmune myasthenia gravis that used the same monoclonal antibody. ${ }^{19}$ The dosage was adapted from the $5 \mathrm{mg} / \mathrm{kg}$ intraperitoneally used in the FNIT mouse model ${ }^{20}$ to a lower dose of $3 \mathrm{mg} / \mathrm{kg}$ since FcRn-ab administration route was changed to IV to avoid possible fetal damage.

\section{Processing of Brain and Blood Samples}

In subsets of mice, brain and blood from fetuses and blood from pregnant mice were collected on day 17 of gestation
(E17, figure 1). Fetal brains were fixed with $4 \%$ paraformaldehyde for 1 hour and cryopreserved in $40 \%$ glucose for 48 hours. Then, brains were embedded in optimal cutting temperature compound and snapped frozen in isopentane chilled with liquid nitrogen. Blood samples were centrifuged to obtain serum.

\section{Antibody Determination in Blood From Pregnant Mice}

The presence of human NMDAR antibodies in blood from pregnant mice was demonstrated by CBA with fixed HEK293T cells expressing GluN1/2B subunits of the NMDAR, as reported. ${ }^{1}$ Briefly, transfected HEK cells were blocked and coincubated with the collected serum sample (1: 10) and with a commercial GluN1 monoclonal mouse antibody (MAB363, 1:20.000, Sigma-Aldrich, St. Louis, MO) at $4^{\circ} \mathrm{C}$ overnight. Then, cells were washed and immunolabeled with Alexa Fluor 488 goat anti-human IgG (A11013) and Alexa Fluor 594 goat anti-mouse IgG (A11005; both diluted 1:1000, from Thermo Fisher, Waltham, MA) as secondary antibodies for 1 hour at room temperature (RT). After washing, coverslips were mounted and scanned under a Zeiss LSM 710 confocal microscope (Carl Zeiss GmbH, Jena, Germany).

\section{Determination of Human IgG, NMDAR Clusters, and Cortical Plate Thickness in Fetal Brains}

To determine whether FcRn blockade prevented human NMDAR antibodies injected to pregnant mice from reaching the brain of fetuses, E17 brain tissue sections were blocked with $1 \%$ bovine serum albumin for 1 hour at RT and then incubated with the same Alexa Fluor 488 goat anti-human IgG as above diluted at 1:1000 for 2 hours at RT. The fluorescence intensity in the developing hippocampus was quantified using Imaris suite v.8.1 software (Oxford Instruments, Belfast,

Figure 1 Experimental Design

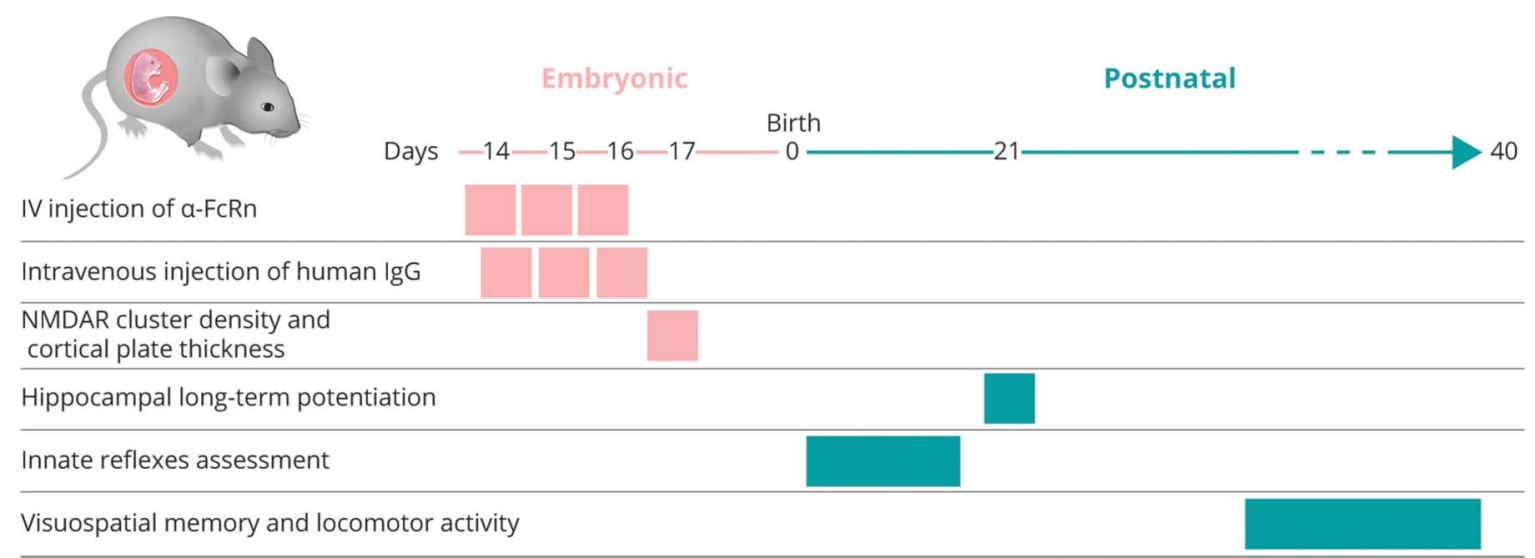

IV injection of FcRn-ab (or saline solution) was performed on gestational days E14, E15, and E16; 6 hours before the administration of controls' or patients' IgG on these days. Fetal brain samples were collected on E17 for immunohistochemical studies of NMDAR cluster density and cortical plate thickness. Electrophysiology to determine hippocampal long-term potentiation was performed on PD 21. Newborns were assessed daily for neurodevelopmental milestones of innate reflexes from birth until day 12 on alternate days (surface righting [PDs 1, 3, 5, 7, 9, and 11] and negative geotaxis [days 2, 4, 6, 8, 10, and 12]). After breastfeeding withdrawal (day 21), mice underwent a simplified battery of behavioral tests at age 1 month including novel object location task and locomotor activity measurement. Gestational period is marked in pink and postnatal period in green. FcRn-ab = FcRn antibody; NMDAR = NMDA receptor; PD $=$ postnatal day. 
United Kingdom). Mean intensity of IgG immunostaining in control animals was defined as $100 \% .^{16}$

To determine whether treatment of pregnant mice with FcRn-ab abrogated the effects of patients' antibodies on the number of clusters of NMDAR and postsynaptic density protein 95 (PSD95) in fetuses, nonpermeabilized 5- $\mu \mathrm{m}$-thick brain sections were blocked as above and serially incubated with a human CSF NMDAR antibody sample (1:20, used as primary antibody) for 2 hours at RT and the secondary Alexa Fluor 488 goat anti-human IgG (1:1000, A11013, Thermo Fisher) for 1 hour at RT. Tissue sections were then permeabilized with $0.3 \%$ Triton X-100 for 10 minutes at RT and serially incubated with rabbit polyclonal antiPSD95 (1:250, ab18258 Abcam, Cambridge, United Kingdom) overnight at $4^{\circ} \mathrm{C}$ and the corresponding secondary Alexa Fluor 594 goat anti-rabbit IgG (1:1000, A-11012, Thermo Fisher) for 1 hour at RT. Slides were then mounted with ProLong Gold antifade reagent, containing 6-diamidino-2-phenylindole dihydrochloride (DAPI, P36935; Thermo Fisher) and results scanned with the Zeiss LSM710 confocal microscope (Carl Zeiss) with EC-Plan NEOFLUAR CS 100x/1.3 NA oil objective. Standardized z-stacks including 25 optical images were acquired from 5 different areas of the developing hippocampus. Images were then deconvolved using theoretical point spread functions of Huygens Professional 17.04 software (Scientific Volume Imaging, Hilversum, NL). The median density of clusters of NMDAR or PSD95 was obtained using a spot detection algorithm from Imaris 8.1 software (Oxford instruments, Belfast, United Kingdom) and the cluster density expressed as spots $/ \mu \mathrm{m}{ }^{3}$ Three-dimensional colocalization of clusters (e.g., NMDAR and PSD95) was performed using a spot colocalization algorithm implemented in Imaris. Synaptic localization was defined as colocalization of NMDAR with PSD95 and expressed as colocalized spots/ $\mu \mathrm{m}^{3}$ For each experimental group, the median cluster density of total cell surface and synaptic NMDAR and PSD95 were normalized to that of brains of fetuses exposed to controls' IgG (100\%). The effects of FcRn-ab treatment on the thickness of the cortical plate were examined in DAPI-stained E17 fetal sagittal brain sections, acquired by confocal microscopy, and quantified using Fiji ImageJ software (fiji.sc/Fiji) as previously reported. ${ }^{12,16}$

\section{Field Potential Recordings and Analysis of Hippocampal LTP and Paired-Pulse Facilitation} Acute sections of the hippocampus obtained on PDs 19-23 were used to determine long-term plasticity by the classical paradigm of theta-burst stimulation at the Schaffer collateral and field potential recording at the CA1 dendritic area. We recently reported this technique applied to the current model of placental transfer of NMDAR antibodies. ${ }^{16,23}$

\section{Neurobehavioral Assessment in Postnatal and Early Adult Stages}

From birth to PD 12, newborn pups were assessed daily for achievement of innate reflexes on alternate days, that is, surface body righting on PDs 1, 3, 5, 7, 9, and 11; and negative geotaxis on PDs 2, 4, 6, 8, 10, and 12; from a simplified Fox battery for developmental milestones previously reported. ${ }^{25}$
After breastfeeding withdrawal at PD 21, subsets of mice underwent a battery of behavioral tests consisting of novel object location (NOL) test (PD 35) and locomotor activity assessment (PD 36) around age 1 month. Selection and timing of these tasks were based on findings from our previously reported animal model of placental transfer of NMDAR antibodies. ${ }^{16}$ All experiments were performed by researchers blinded to animals' experimental conditions, as reported. ${ }^{13,16}$

\section{Statistical Analysis}

Comparison of human IgG intensity in the brain of fetuses among the 3 experimental groups was performed with 1-way ANOVA with Tukey correction for multiple comparisons. Comparison of confocal densities of NMDAR and PSD95 clusters and cortical plate thickness among the 3 experimental groups was analyzed with the Welch ANOVA test and Dunnett T3 corrections for multiple comparisons of small $\mathrm{n}$ groups (lower than 50) comparing normally distributed nonhomoscedastic populations. Comparison of field excitatory postsynaptic potential (fEPSP) slope recordings in mice born to mothers from the indicated experimental groups was assessed by the Kruskal-Wallis test comparing ranks (as populations were not normally distributed according to D'Agostino-Pearson test) with Dunn corrections for multiple comparisons. For behavioral paradigms, longitudinal analyses were performed by generalized estimated equations (GEEs) using an $\mathrm{AR}(1)$ matrix to account for intraindividual correlations. All models include litter size, group, and interaction group by time as fixed factors. Pairwise comparison in interaction factor was used to analyze differences between group time by time, showed as estimated means and their 95\% CIs. Mean values of fEPSP slope change recordings and of times for developmental reflexes were presented with standard error of the mean $( \pm$ SEM). All experiments were assessed for outliers with Robust regression and Outlier removal (ROUT) method applying $\mathrm{Q}=1 \%$. In all statistical analyses, we used a 2-sided type I error of $5 \%$. All tests were performed using GraphPad Prism (Version 8, San Diego, CA) or SPSS (Version 25, IBM Corp., Armonk, NY) for GEE models.

\section{Data Availability}

Data supporting these findings are available on reasonable request.

\section{Results}

\section{Treatment With FcRn-ab Prevents Placental Transfer of Human IgG}

Serum samples of E17 pregnant mice that received patients' IgG, but not those that received controls' IgG, showed human IgG binding to HEK293T cells expressing NMDARs. These antibodies were detectable in serum of pregnant mice that received patients' IgG regardless of whether they had been treated a few hours earlier with FcRn-ab (Figure 2A). In contrast, only serum samples from E17 fetuses whose mothers had received patients' IgG but were not treated with FcRn-ab 
Figure 2 Treatment With FcRn-ab Blocks the Placental Transfer of Intravenously Administered Patients' IgG and Their Presence in the Fetal Brain

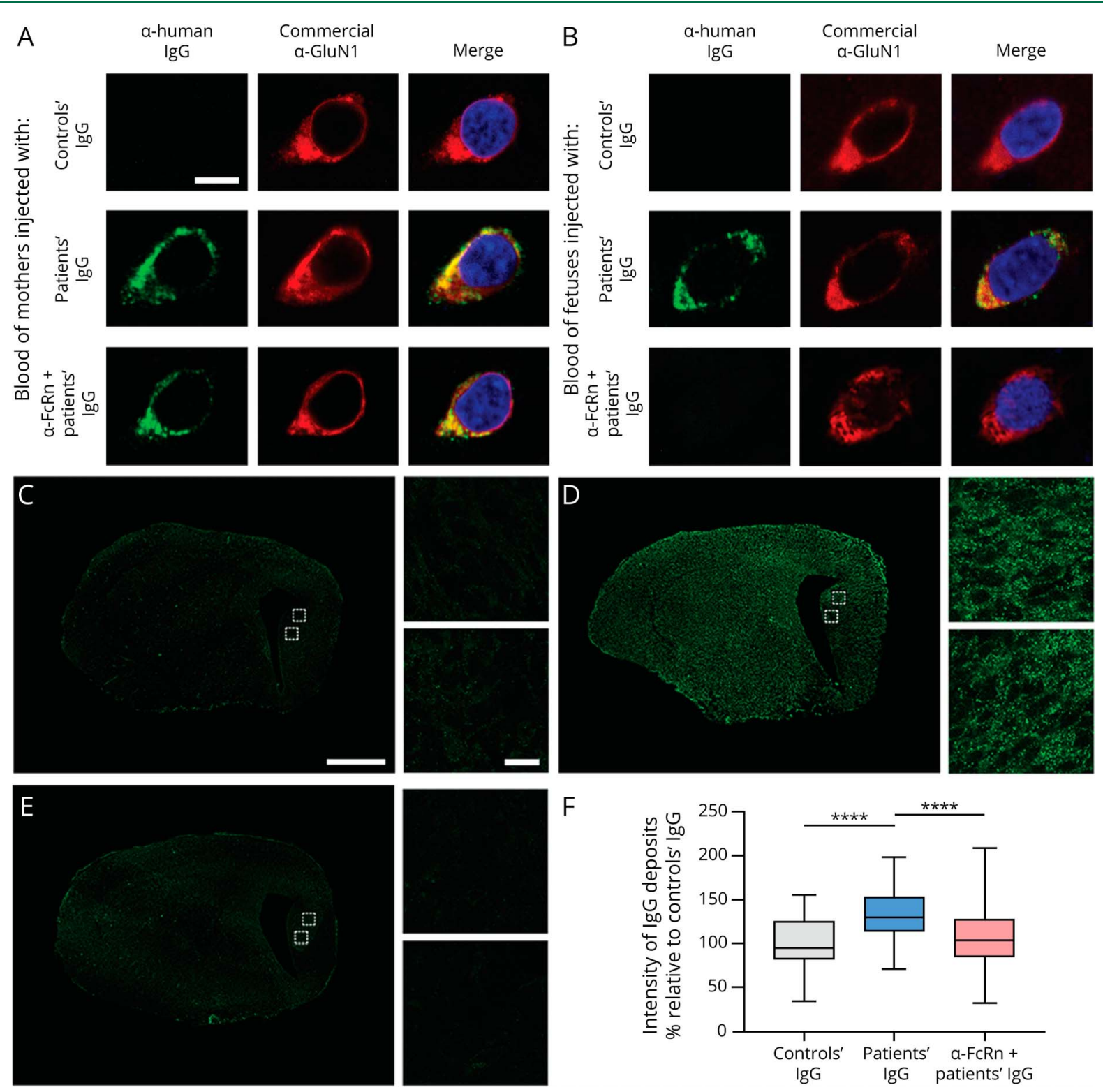

(A and B) Representative images of HEK293T cells expressing NMDARs immunolabeled with human IgG contained in serum of pregnant mice injected with controls' IgG or patients' IgG with or without pretreatment with FcRn-ab (A) and from serum of their fetuses (B) (all studies conducted on day E17). Scale bar = $10 \mu \mathrm{m}$. (C-E) Representative human IgG immunolabeling in E17 fetal brain sections of animals whose mothers were administered controls' IgG (C), patients' IgG (D), or patients' IgG along with pretreatment with FcRn-ab (E); the 2 insets (small squares in the developing hippocampus) are shown enlarged on the right of each panel. Scale bar whole brain $=50 \mu \mathrm{m}$, insets $=10 \mu \mathrm{m}$. (F) Quantification of human IgG immunofluorescence intensity in the developing hippocampus of E17 fetal brains whose mothers were administered controls' IgG, patients' IgG, or patients' IgG along with pretreatment with FcRn-ab. Controls' IgG, $n=8$; patients' IgG, $n=7$; patients' IgG treated with FcRn-ab, $n=7$. Mean intensity of IgG immunofluorescence in the brain of mice exposed to controls' IgG was defined as $100 \%$. Data presented in box plots show the median, 25th, and 75th percentiles; whiskers indicate minimum and maximum. Significance of the treatment effect was assessed by 1-way ANOVA and multiple comparisons with Tukey corrections. $* \star \star \star p p<0.0001$. FcRn-ab $=$ FcRn antibody; NMDAR $=$ NMDA receptor.

harbored NMDAR antibodies (Figure 2B). Moreover, on day E17, these fetuses showed a significant increase in human IgG fluorescence in the developing hippocampus compared with fetuses of mothers that received the same patients' IgG but were treated with $\mathrm{FcRn}-\mathrm{ab}(p<0.0001)$ or the fetuses of mothers that received controls' IgG $(p<0.0001)$ (Figure 2, $\mathrm{C}-\mathrm{F})$. These findings show that treatment with FcRn-ab resulted in an effective blockade of placental transfer of human NMDAR antibodies.
FcRn-ab Administration to Pregnant Mice Abrogates Patients' IgG-Mediated Reduction of NMDAR Clusters and Thinning of the Cortical Plate in the Fetal Brain

Analysis of the density of NMDAR clusters showed that fetuses from mothers that received patients' IgG without pretreatment with FcRn-ab had a significant decrease of cluster density of total cell surface and synaptic NMDARs compared with fetuses of mothers that received controls' IgG 
(72.95\% total and $78.63 \%$ synaptic clusters vs $100 \%$ total and synaptic clusters in controls; both, $p<0.0001)$ as expected from this model. ${ }^{16}$ This decrease of NMDAR clusters was largely prevented when the mothers were treated with $\mathrm{FcRn}$ $\mathrm{ab}$ (fetuses from FcRn-ab-treated mothers $94.17 \%$ total and $102.4 \%$ synaptic NMDAR clusters vs the indicated values of fetuses from nontreated mothers, $p<0.0001$ ) (Figure 3, A-C). Patients' IgG also caused a significant thinning of the fetal cortical plate on E17 (fetuses from mothers that received patients' IgG, $15.54 \%$ thinner plate compared with fetuses from mothers that received controls' $\mathrm{IgG}, 100 \% ; p=0.0004$ ). This thinning of the plate was abrogated in fetuses of mothers that received patients' IgG but were pretreated with FcRn-ab (fetuses from $\mathrm{FcRn}$-ab-treated mothers $103 \%$ vs the indicated value of fetuses from nontreated mothers, $p=0.0002$ ) (Figure 3, D and E).

\section{Treatment of Pregnant Mice With FcRn-ab Prevents the Impairment of Hippocampal LTP Caused by Patients' IgG in the Young Offspring} Assessment of fEPSPs showed that on PD 21, mice that had been exposed in utero to patients' IgG had a significant impairment in hippocampal long-term potentiation (LTP) formation compared with mice exposed in utero to controls' IgG $(p<0.0001)$. In contrast, mice whose mothers received the same patients' IgG but were treated with $\mathrm{FcRn}$-ab did not show impairment of LTP (FcRn-ab-treated vs nontreated mothers, $p<0.0001$ ) (Figure 4, A-C). Paired-pulsed facilitation was not affected by patients' IgG, as previously reported in this model ${ }^{16}$ (data not shown). Overall, these experiments show severe impairment of postsynaptic, but not presynaptic, plasticity in animals exposed in utero to patients' $\operatorname{IgG}$ and that these antibody effects were abrogated when the mothers were treated with FcRn-ab.

\section{Treatment of Pregnant Mice With FcRn-ab Prevents the Developmental Delay in Innate Reflexes Caused by Patients' IgG in Newborns}

To determine whether FcRn-ab also prevented neurodevelopmental abnormalities, we assessed the neurodevelopment of newborns whose mothers received during gestation patients' IgG with or without FcRn-ab treatment. Newborn pups exposed in utero to patients' IgG, but not to controls' IgG, showed longer times for proper body righting (Figure 5A, PDs 5 and 9) and for completing a $180^{\circ}$ turn in the negative geotaxis reflex test (Figure 5B, PDs 6, 8, and 10). These neurodevelopmental delayed alterations induced by patients' IgG did not occur in the young offspring of mothers treated with FcRn-ab (Figure 5, A and B).

\section{Blockade of Placental Transfer of Patients' IgG Prevents Behavioral Alterations in Early Adulthood}

We then compared the effects of patients' IgG on the behavior of mice whose mothers were treated or not with $\mathrm{FcRn}-\mathrm{ab}$. At age 1 month, mice exposed in utero to patients' IgG, but not those exposed to controls' IgG, showed a significant decrease in the NOL index, indicating an impairment in visuospatial memory $(p=0.049)$ (Figure 5C). In contrast, mice whose mothers were treated with $\mathrm{FcRn}$-ab did not develop this memory deficit (FcRn-ab-treated vs nontreated mothers, $p=$ 0.019 ). No significant difference in motor activity was noted among the different groups, including local (Figure 5D), horizontal and vertical (rearing) activities (data not shown). Overall, these findings confirm those of our previous study ${ }^{16}$ and demonstrate that in this animal model, the alterations of memory caused by patients' IgG can be prevented by blocking the placental transfer of antibodies with FcRn-ab.

\section{Discussion}

We have used a mouse model of placental transfer of IgG from patients with anti-NMDAR encephalitis to show that FcRn-ab administration blocked the maternofetal $\operatorname{IgG}$ transfer and prevented the alterations previously reported in this model, which include (1) a decrease of the cluster density of total cell surface and synaptic NMDARs in the fetus, (2) thinning of the cortical plate in the developing brain, (3) delay in neonatal developmental reflexes, (4) impairment of hippocampal LTP in newborns, and (5) deficit in visuospatial memory in the offspring. ${ }^{16}$

The $\mathrm{FcRn}$ is an $\mathrm{Fc} \mathrm{IgG}$ receptor responsible for preventing early lysosomal IgG degradation in vascular endothelial cells, therefore extending the half-life of IgG in serum. ${ }^{18} \mathrm{FcRn}$-IgG interactions are $\mathrm{pH}$ dependent: at slightly acidic $\mathrm{pH}$ environments (e.g., in early endosomes), IgG undergoes a conformational change that enables its $\mathrm{Fc}$ region to bind the $\mathrm{FcRn}$, whereas at physiologic $\mathrm{pH}$ in the cell surface, $\mathrm{FcRn}$ bound IgG is released back into circulation. ${ }^{26-28}$ This FcRn mechanism also mediates placental IgG transcytosis, allowing passive humoral immunization from mother to fetus during pregnancy. ${ }^{29}$ Moreover, a similar mechanism of transcytosis applies to other cell barriers such as the intestinal epithelium ${ }^{26}$ or the BBB. ${ }^{30}$

FcRn blocking strategies are of special interest for the treatment of autoimmune diseases in which the autoantibodies are pathogenic. For example, in preclinical studies, monoclonal FcRn-abs were able to reduce IgG serum half-life and decrease the severity of symptoms in animal models of autoimmune arthritis, ${ }^{31}$ myasthenia gravis, ${ }^{19}$ and epidermolysis bullosa acquisita. $^{32}$

In pregnant patients with autoantibody-mediated diseases, pathogenic IgG antibodies are also transferred via placental $\mathrm{FcRn}$ to fetus. Blockade of FcRn-IgG binding using a monoclonal $\mathrm{FcRn}$-ab prevented IgG from reaching fetal circulation in an ex vivo perfusion model of human placenta. ${ }^{33}$ Furthermore, a previous animal model of antibody-mediated FNIT showed that treatment of the mothers with an FcRn-ab prevented the pathogenic effects of the antibodies in the pups. ${ }^{20}$ Despite the differences in the experimental design and 
Figure 3 FcRn-ab Administration to Pregnant Mice Abrogates Patients' IgG-Mediated Reduction of NMDAR Clusters and Thinning of the Cortical Plate in the Fetal Brain

A
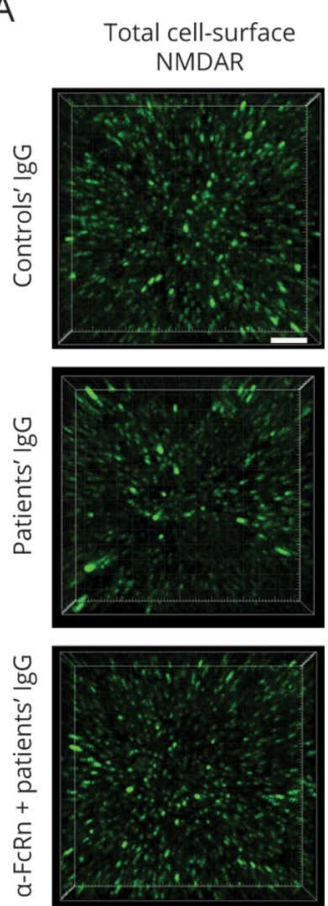

D
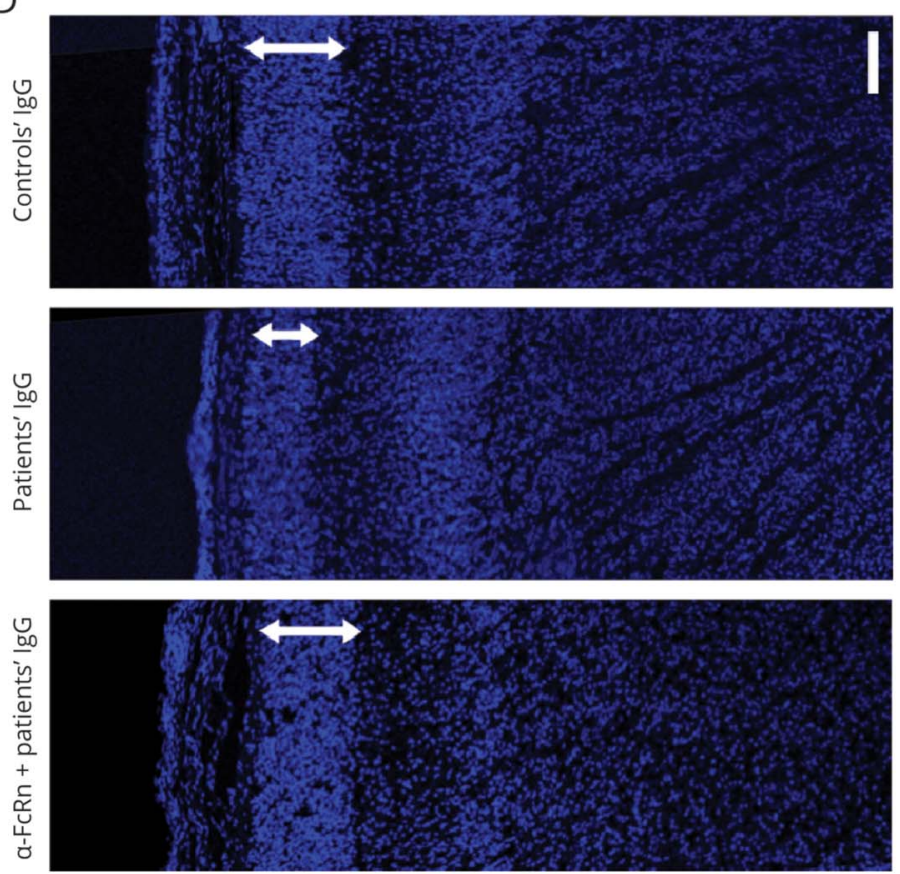

B. Total cell-surface NMDAR

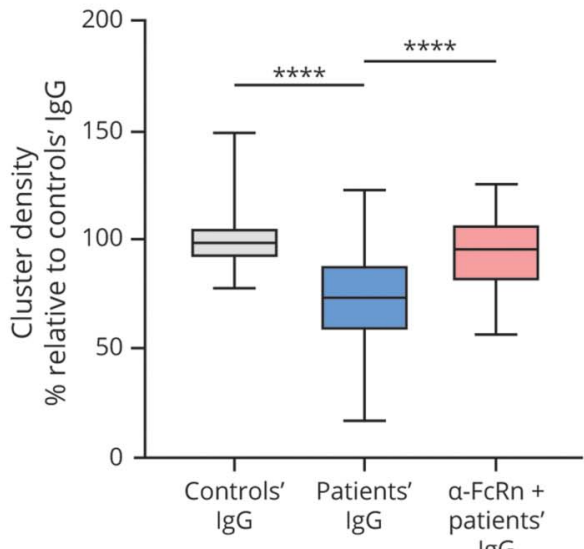

C. Synaptic NMDAR

IgG

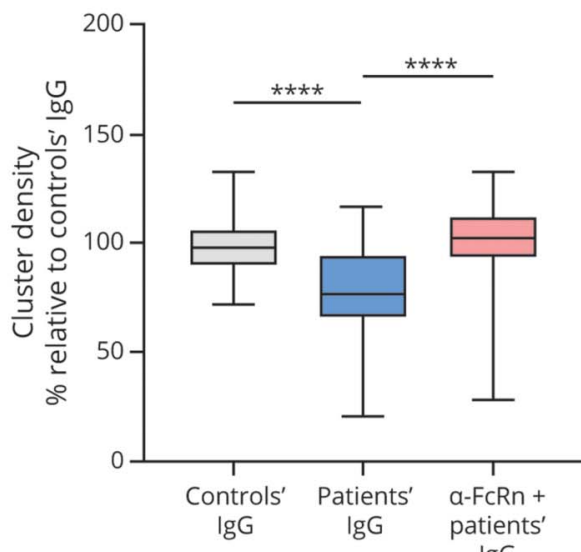

E. Cortical plate thickness

IgG

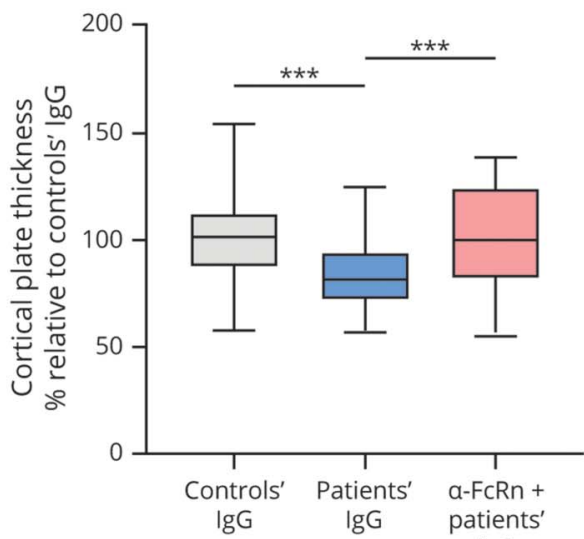

IgG

(A) Representative 3-dimensional projections and analysis of the density of total cell surface NMDAR clusters (green), PSD95 (red), and synaptic NMDAR clusters (white, defined as those that colocalized with PSD95) in the developing hippocampus area in E17 animals whose mothers received controls' IgG, patients' IgG, or patients' IgG along with pretreatment with FcRn-ab. Scale bar $=2 \mu \mathrm{m}$. (B and C) Quantification of total cell surface (B) and synaptic (C) NMDAR cluster density in brains obtained on gestational day E17 from animals whose mothers received controls' IgG, patients' IgG, or patients' IgG along with pretreatment with FcRn-ab. Median of NMDAR clusters in mice exposed to controls' IgG was defined as $100 \%$. Controls' IgG, $n=7 ;$ patients' IgG, $n=7 ;$ patients' IgG along with pretreatment with FcRn-ab, $n=6$. (D) Representative cortical plate thickness (stained with DAPI) in E17 brains of fetuses whose mothers received controls' IgG, patients' IgG, or patients' IgG along with pretreatment with FcRn-ab. Scale bars $=100 \mu \mathrm{m}$. (E) Quantification of cortical plate thickness in E17 brains of fetuses whose mothers received controls' IgG, patients' IgG, or patients' IgG along with pretreatment with FcRn-ab. Controls' IgG, $\mathrm{n}=8$; patients' IgG, $n=7$; patients' IgG along with pretreatment with FcRn-ab, $n=7$. Mean thickness of the cortical plate or the indicated cortical layers in mice exposed in utero to controls' IgG was defined as $100 \%$. Data presented in box plots show the median, 25th, and 75 th percentiles; whiskers indicate minimum and maximum. Significance of the treatment effect was assessed by the Welch ANOVA test and Dunnett T3 corrections for multiple comparisons. * $* \star p<0.001$ and $\star \star \star \star x p 0.0001$. FcRn-ab = FcRn antibody; NMDAR = NMDA receptor. 
A

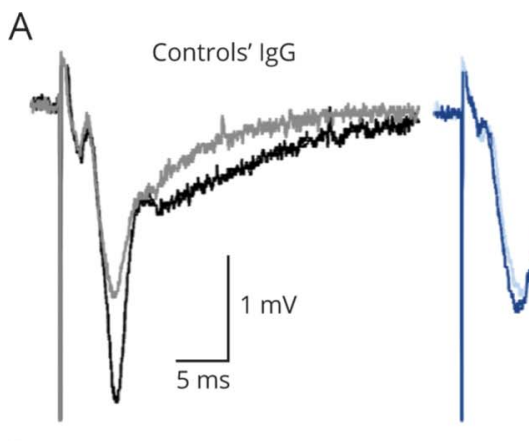

$\mathrm{B}$

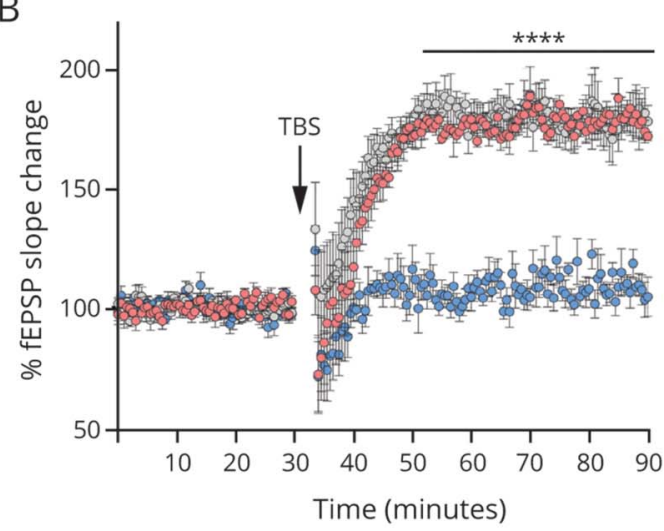

Patients' IgG

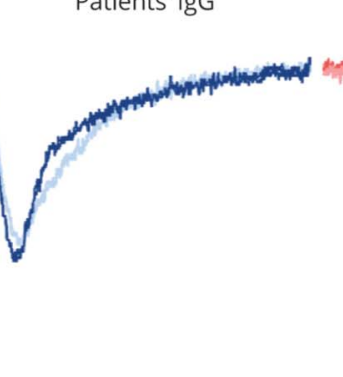

C

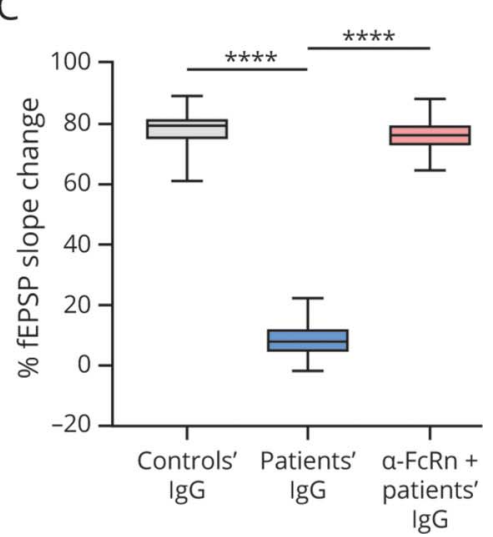

(A) Example traces of individual recordings showing baseline recordings before LTP induction (gray, light blue, and pink traces) and after LTP (black, dark blue, and red traces). Slope and peak amplitude of fEPSPs are increased after TBS in the hippocampus of PD 21 mice whose mothers received controls' IgG. In contrast, manifestation of LTP is strongly impaired in mice whose mothers received patients' IgG and therefore were exposed in utero to patients' IgG. Note that in mice whose mothers received the same patients' IgG but were treated with FcRn-ab, the slope and peak amplitude of fEPSPs are similar to those of controls. (B) Time course of fEPSP recordings demonstrating a robust increase in fEPSP slope in the hippocampus of PD 21 mice whose mothers received controls' IgG ( $n=$ 6 recordings from 5 animals, gray dots) or patients' IgG along with pretreatment with FcRn-ab ( $\mathrm{n}=5$ recordings from 5 animals, pink dots), compared with that of mice whose mothers received patients IgG but were not treated with FcRn-ab ( $=5$ recordings from 5 animals, blue dots); the indicated changes were stable throughout the recording period after TBS (arrow). In animals exposed in utero to patients' IgG, the induction of LTP is markedly impaired. Average fEPSP values are presented as mean \pm SEM. C: Quantitative analysis of the fEPSP slope in the hippocampus of 21-day postnatal mice whose mothers received controls' IgG, patients' IgG, or patients' IgG along with pretreatment with FcRn-ab. Mean fEPSP slope before TBS was defined as 100\%, and post-TBS fEPSP slope data were normalized to it for each group. The number of animals is the same as in panel $B$. The box plots show the median, 25th, and 75th percentiles; whiskers indicate minimum and maximum values. Significance of the treatment effect was assessed by the Kruskal-Wallis test with Dunn corrections for multiple comparisons. $* * \star * p<0.0001$. FcRn-ab $=$ FcRn antibody; fEPSP = field excitatory postsynaptic potential; LTP = long-term potentiation; NMDAR = NMDA receptor; $P D$ $=$ postnatal day; TBS = theta-burst stimulation. location of the target antigens (periphery vs CNS), our data resemble that of the FNIT model because FcRn blockade with the same FcRn-ab prevented the pathogenic effects of NMDAR antibodies in mice fetuses and newborns.

Our study has limitations; the current model lacks the inflammatory component associated with anti-NMDAR encephalitis, which can potentially alter the placental transfer of patients' antibodies or directly affect the developing fetal brain. Thus, future studies should address whether FcRn inhibitors such as the FcRn-ab used here work similarly in the presence of systemic inflammation. Moreover, the FcRn expressed in the BBB facilitates IgG efflux from the brain to blood. $^{30,34}$ Therefore, one can speculate that blocking the FcRn of a well-developed BBB can potentially increase the amount of pathogenic antibodies in the brain; however, in the pregnancy model, the pathogenic antibodies have to reach the brain from systemic blood, which in turn is largely prevented by the mature $B B B$.

The use of FcRn-abs has already reached clinical trial stage. Rozanolixizumab, a high-affinity FcRn IgG4 antibody, and M281, also known as nipocalimab, are currently in phase III (NCT03971422) and phase II trials (NCT03772587) for the treatment of myasthenia gravis. ${ }^{35,36}$ Nipocalimab, an IgG1 antibody with a high-safety profile, ${ }^{37}$ is currently used in a phase II study (NCT03842189) in pregnant women at high risk of early-onset severe hemolytic disease of the fetus and newborn. ${ }^{38}$ However, efficiently blocking placental IgG transfer may lead to a transient hypogammaglobulinemia in the infant. If so, this newborn with reduced maternal protective antibodies would be more prone to infections until its 
Figure 5 Treatment of Pregnant Mice With FcRn-ab Prevents Developmental Delay in Innate Reflexes and Behavioral Alterations Caused by Patients' IgG in Offspring

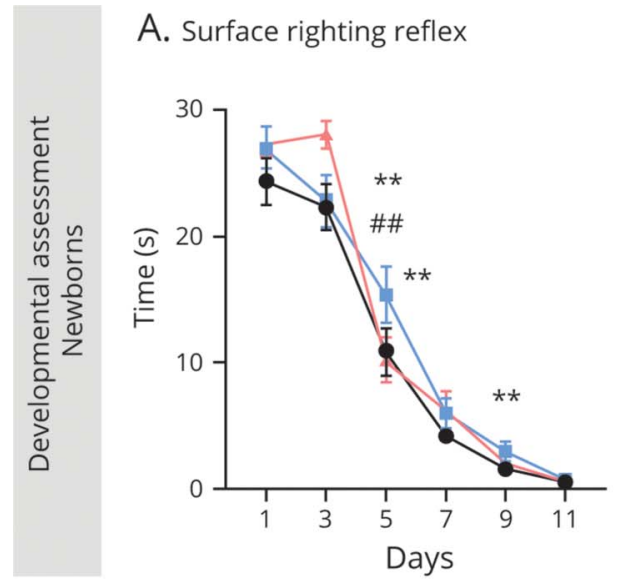

C. Novel object location test

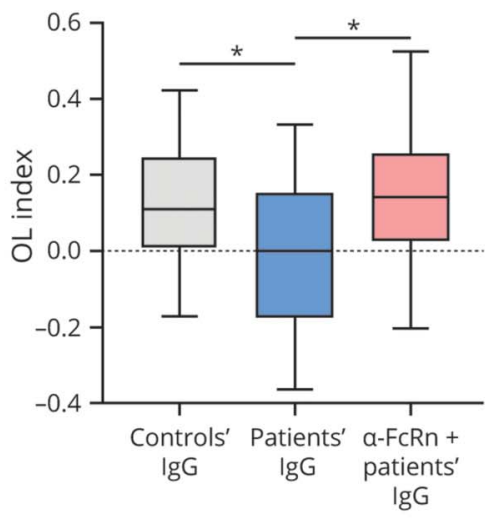

B. Negative geotaxis

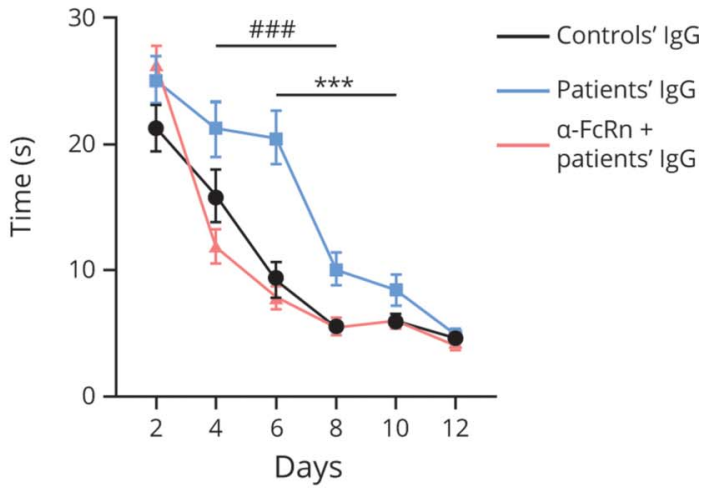

D. Local activity

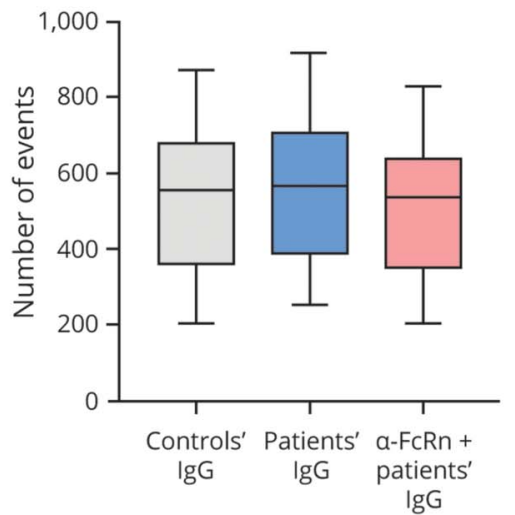

(A and B) Developmental milestones assessment (from birth to day 12) of innate reflexes in mice whose mothers were administered controls' lgG (black), patients' IgG (blue), or patients' IgG along with pretreatment with FcRn-ab (red). (A) Time needed for body righting using the surface righting reflex test (days 1 , $3,5,7,9$, and 11 ), and (B) time needed for $180^{\circ}$ turning to head up position using the negative geotaxis reflex (days $2,4,6,8,10$, and 12 ). Number of mice whose mothers received controls' IgG = 30; number of mice whose mothers received patients' $\lg G=25$, number of mice whose mothers received patients' $\mid \mathrm{g} G$ and were treated with $\mathrm{FcRn}-\mathrm{ab}=35$. Data are represented as mean $\pm \mathrm{SEM}$. Significance of the treatment effect was assessed with estimated means and ( $95 \% \mathrm{Cl}$ ) by a GEE adjusted model. Controls' IgG vs patients' IgG: $* \star p<0.01$ and $* \star \star x<0.001$. Patients' IgG vs patients' IgG along with pretreatment with FcRn-ab: \#\#p< 0.01 and $\# \# \# p<0.001$. (C and D) Behavioral tests performed at age 1 month including novel object location index (C) and number of local activity events from the locomotor activity assessment (D). Number of mice whose mothers received controls' $\mathrm{IgG}=25$; mice whose mothers received patients' $\mathrm{IgG}=17$, and mice whose mothers received patients' IgG along with pretreatment with $\mathrm{FcRn}-\mathrm{ab}=31$. Data are represented as box plots with median, 25th, and 75th percentiles; whiskers indicate minimum and maximum values. Significance of the treatment effect was assessed with estimated means and (95\% Cl) by a GEE model. ${ }^{*} p<$ 0.05. FcRn-ab = FcRn antibody; GEE = generalized estimated equation.

own immune system restores IgG levels, at around age 6 months, as reported in pregnancies of patients with genetic primary immunodeficiencies ${ }^{39}$ or in those with immunosuppressive treatment during pregnancy (e.g., rituximab). ${ }^{40}$ Although no signs of infection were observed in the newborn mice that received FcRn-ab in our model, the possibility of IgG replacement therapy in the infants should be considered.

Overall, our findings and experience from ongoing clinical trials support the potential therapeutic use of FcRn blockade in pregnant patients with anti-NMDAR encephalitis. Similar implications are likely applicable to other antibody-mediated encephalitis. Tasks for the future are to determine the effects of NMDAR antibodies in models of active immunization (which should be accompanied by inflammation), the frequency of synaptic, developmental, and behavioral alterations in the offspring, and whether they can be prevented by FcRn blockade.

\section{Study Funding}

This study was funded by Plan Nacional de $\mathrm{I}+\mathrm{D}+\mathrm{I}$ and cofinanced by the Instituto de Salud Carlos III (ISCIII) Subdirección General de Evaluación y Fomento de la Investigación Sanitaria and the Fondo Europeo de Desarrollo Regional (FEDER) (FIS PI20/00197, J.D.; PI20/ 00280, J.P.); Project Integrative of Excellence (PIE 16/ 00014) and Juan Rodés grant (JR17/00012, E.M.-H.); Centro de Investigación Biomédica en Red de Enfermedades Raras (CIBERER; \#CB15/00010); La Caixa Foundation (ID 100010434, under the agreement LCF/PR/HR17/ 52150001); The Safra Foundation (J.D.) and Fundació 
CELlEX (J.D.); Centres de Recerca de Catalunya (CERCA) program, Pla Estratègic de Recerca i Innovació en Salut (PERIS, SLT002/16/00346, J.P.), and Agència de Gestió d'Ajuts Universitaris i de Recerca (FI-AGAUR) grant program (2020 FI_B2 00208, A.G.-S.) by La Generalitat de Catalunya (J.R.); and Basque Government Doctoral Fellowship Program (PRE_2020_2_0219; E.M.).

\section{Disclosure}

A. García-Serra, M. Radosevic, J. Ríos, E. Aguilar, E. Maudes, J. Landa, L. Sabater, E. Martinez-Hernandez, and J. Planagumà report no disclosures. J. Dalmau receives royalties from Athena Diagnostics for the use of Ma2 as an autoantibody test and from Euroimmun for the use of NMDA, GABAB receptor, GABAA receptor, DPPX and IgLON5 as autoantibody tests. Go to Neurology.org/NN for full disclosures.

\section{Publication History}

Received by Neurology: Neuroimmunology \& Neuroinflammation April 27, 2021. Accepted in final form June 15, 2021.

\section{Appendix Authors}

\begin{tabular}{|c|c|c|}
\hline Name & Location & Contribution \\
\hline $\begin{array}{l}\text { Anna García- } \\
\text { Serra, MSc }\end{array}$ & $\begin{array}{l}\text { Institut d'Investigacions } \\
\text { Biomèdiques August Pi i } \\
\text { Sunyer (IDIBAPS), Hospital } \\
\text { Clínic, Universitat de } \\
\text { Barcelona, Spain }\end{array}$ & $\begin{array}{l}\text { Drafting/revision of the } \\
\text { manuscript for content, } \\
\text { including medical writing } \\
\text { for content; major role in } \\
\text { the acquisition of data; and } \\
\text { analysis or interpretation of } \\
\text { data }\end{array}$ \\
\hline $\begin{array}{l}\text { Marija } \\
\text { Radosevic, } \\
\text { PhD }\end{array}$ & $\begin{array}{l}\text { Institut d'Investigacions } \\
\text { Biomèdiques August Pi i } \\
\text { Sunyer (IDIBAPS), Hospital } \\
\text { Clínic, Universitat de } \\
\text { Barcelona, Spain }\end{array}$ & $\begin{array}{l}\text { Major role in the acquisition } \\
\text { of data }\end{array}$ \\
\hline
\end{tabular}

\begin{tabular}{|c|c|c|}
\hline José Ríos, MSc & $\begin{array}{l}\text { Medical Statistics Core } \\
\text { Facility, IDIBAPS and } \\
\text { Hospital Clínic, Barcelona. } \\
\text { Spain; Biostatistics Unit, } \\
\text { Faculty of Medicine, } \\
\text { Universitat Autònoma de } \\
\text { Barcelona, Spain }\end{array}$ & $\begin{array}{l}\text { Analysis or interpretation of } \\
\text { data }\end{array}$ \\
\hline $\begin{array}{l}\text { Esther } \\
\text { Aguilar, BS }\end{array}$ & $\begin{array}{l}\text { Institut d'Investigacions } \\
\text { Biomèdiques August Pi i } \\
\text { Sunyer (IDIBAPS), Hospital } \\
\text { Clínic, Universitat de } \\
\text { Barcelona, Spain }\end{array}$ & $\begin{array}{l}\text { Major role in the acquisition } \\
\text { of data }\end{array}$ \\
\hline $\begin{array}{l}\text { Estibaliz } \\
\text { Maudes, MSc }\end{array}$ & $\begin{array}{l}\text { Institut d'Investigacions } \\
\text { Biomèdiques August Pi i } \\
\text { Sunyer (IDIBAPS), Hospital } \\
\text { Clínic, Universitat de } \\
\text { Barcelona, Spain }\end{array}$ & $\begin{array}{l}\text { Major role in the acquisition } \\
\text { of data }\end{array}$ \\
\hline $\begin{array}{l}\text { Jon Landa, } \\
\text { MSc }\end{array}$ & $\begin{array}{l}\text { Institut d'Investigacions } \\
\text { Biomèdiques August Pi i } \\
\text { Sunyer (IDIBAPS), Hospital } \\
\text { Clínic, Universitat de } \\
\text { Barcelona, Spain }\end{array}$ & $\begin{array}{l}\text { Major role in the acquisition } \\
\text { of data }\end{array}$ \\
\hline $\begin{array}{l}\text { Lidia Sabater, } \\
\text { PhD }\end{array}$ & $\begin{array}{l}\text { Institut d'Investigacions } \\
\text { Biomèdiques August Pi i } \\
\text { Sunyer (IDIBAPS), Hospital } \\
\text { Clínic, Universitat de } \\
\text { Barcelona, Spain }\end{array}$ & $\begin{array}{l}\text { Major role in the acquisition } \\
\text { of data }\end{array}$ \\
\hline
\end{tabular}

Appendix (continued)

\begin{tabular}{|c|c|c|}
\hline Name & Location & Contribution \\
\hline $\begin{array}{l}\text { Eugenia } \\
\text { Martinez- } \\
\text { Hernandez, } \\
\text { MD, PhD }\end{array}$ & $\begin{array}{l}\text { Institut d'Investigacions } \\
\text { Biomèdiques August Pi i } \\
\text { Sunyer (IDIBAPS), Hospital } \\
\text { Clínic, Universitat de } \\
\text { Barcelona, Spain }\end{array}$ & Study concept or design \\
\hline $\begin{array}{l}\text { Jesús } \\
\text { Planagumà, } \\
\text { PhD }\end{array}$ & $\begin{array}{l}\text { Institut d'Investigacions } \\
\text { Biomèdiques August Pi i } \\
\text { Sunyer (IDIBAPS), Hospital } \\
\text { Clínic, Universitat de } \\
\text { Barcelona, Spain }\end{array}$ & $\begin{array}{l}\text { Major role in the acquisition } \\
\text { of data and study concept } \\
\text { or design }\end{array}$ \\
\hline $\begin{array}{l}\text { Josep Dalmau, } \\
\text { MD, PhD }\end{array}$ & $\begin{array}{l}\text { Institut d'Investigacions } \\
\text { Biomèdiques August Pi i } \\
\text { Sunyer (IDIBAPS), Hospital } \\
\text { Clínic, Universitat de } \\
\text { Barcelona, Barcelona. } \\
\text { Spain; Department of } \\
\text { Neurology, University of } \\
\text { Pennsylvania, Philadelphia; } \\
\text { Institució Catalana de } \\
\text { Recerca i Estudis Avançats } \\
\text { (ICREA), Barcelona, Spain }\end{array}$ & $\begin{array}{l}\text { Drafting/revision of the } \\
\text { manuscript for content, } \\
\text { including medical writing } \\
\text { for content; study concept } \\
\text { or design; and analysis or } \\
\text { interpretation of data }\end{array}$ \\
\hline
\end{tabular}

\section{References}

1. Dalmau J, Gleichman AJ, Hughes EG, et al. Anti-NMDA-receptor encephalitis: case series and analysis of the effects of antibodies. Lancet Neurol. 2008;7(12):1091-1098.

2. Dalmau J, Armangué $\mathrm{T}$, Planagumà $\mathrm{J}$, et al. An update on anti-NMDA receptor encephalitis for neurologists and psychiatrists: mechanisms and models. Lancet Neurol. 2019;18(11):1045-1057.

3. Irani SR, Bera K, Waters $\mathrm{P}$, et al. N-methyl-d-aspartate antibody encephalitis: temporal progression of clinical and paraclinical observations in a predominantly nonparaneoplastic disorder of both sexes. Brain. 2010;133(6):1655-1667.

4. Titulaer MJ, McCracken L, Gabilondo I, et al. Treatment and prognostic factors for long-term outcome in patients with anti-NMDA receptor encephalitis: an observational cohort study. Lancet Neurol. 2013;12(2):157-165.

5. Viaccoz A, Desestret V, Ducray F, et al. Clinical specificities of adult male patients with NMDA receptor antibodies encephalitis. Neurology. 2014;82(7):556-563.

6. Kumar MA, Jain A, Dechant VE, et al. Anti-N-methyl-D-aspartate receptor encephalitis during pregnancy. Arch Neurol. 2010;67(7):884-887.

7. Joubert B, García-Serra A, Planagumà J, et al. Pregnancy outcomes in anti-NMDA receptor encephalitis: case series. Neurol Neuroimmunol Neuroinflamm. 2020;7(3):e668.

8. Xiao X, Gui S, Bai P, et al. Anti-NMDA-receptor encephalitis during pregnancy: a case report and literature review. J Obstet Gynaecol Res. 2017;43(4):768-774.

9. Hughes EG, Peng X, Gleichman AJ, et al. Cellular and synaptic mechanisms of antiNMDA receptor encephalitis. J Neurosci. 2010;30(17):5866-5875.

10. Mikasova L, De Rossi P, Bouchet D, et al. Disrupted surface cross-talk between NMDA and Ephrin-B2 receptors in anti-NMDA encephalitis. Brain. 2012;135(pt 5): 1606-1621.

11. Moscato EH, Peng X, Jain A, et al. Acute mechanisms underlying antibody effects in anti-N-methyl-D-aspartate receptor encephalitis. Ann Neurol. 2014;76(1):108-119.

12. Planagumà J, Leypoldt $\mathrm{F}$, Mannara $\mathrm{F}$, et al. Human $\mathrm{N}$-methyl $\mathrm{D}$-aspartate receptor antibodies alter memory and behaviour in mice. Brain. 2015;138(pt 1):94-109.

13. Planagumà J, Haselmann H, Mannara F, et al. Ephrin-B2 prevents N-methyl-Daspartate receptor antibody effects on memory and neuroplasticity. Ann Neurol. 2016; $80(3): 388-400$.

14. Carceles-Cordon M, Mannara F, Aguilar E, et al. NMDAR antibodies alter dopamine receptors and cause psychotic behavior in mice. Ann Neurol. 2020;88(3):603-613.

15. Jurek B, Chayka M, Kreye J, et al. Human gestational N-methyl-D-aspartate receptor autoantibodies impair neonatal murine brain function. Ann Neurol. 2019;86(5): 656-670.

16. García-Serra A, Radosevic M, Pupak A, et al. Placental transfer of NMDAR antibodies causes reversible alterations in mice. Neurol Neuroimmunol Neuroinflamm. 2021;8(1): e915.

17. Hilderink M, Titulaer MJ, Schreurs MWJ, et al. Transient anti-NMDAR encephalitis in a newborn infant due to transplacental transmission. Neurol Neuroimmunol Neuroinflamm. 2015;2(4):1-2.

18. Roopenian DC, Christianson GJ, Sproule TJ, et al. The MHC class I-like IgG receptor controls perinatal IgG transport, IgG homeostasis, and fate of IgG-fc-coupled drugs. J Immunol. 2003;170(7):3528-3533.

19. Liu L, Garcia AM, Santoro H, et al. Amelioration of experimental autoimmune myasthenia gravis in rats by neonatal FcR blockade. J Immunol. 2007;178(8):5390-5398.

20. Chen P, Li C, Lang S, et al. Animal model of fetal and neonatal immune thrombocytopenia: role of neonatal $\mathrm{Fc}$ receptor in the pathogenesis and therapy. Blood. 2010; 116(18):3660-3668. 
21. Coutinho E, Jacobson L, Shock A, et al. Inhibition of maternal-to-fetal transfer of IgG antibodies by FcRn blockade in a mouse model of arthrogryposis multiplex congenita. Neurol Neuroimmunol Neuroinflamm. 2021;8(4):e1011.

22. Moscato EH, Jain A, Peng X, et al. Mechanisms underlying autoimmune synaptic encephalitis leading to disorders of memory, behavior and cognition: insights from molecular, cellular and synaptic studies. Eur J Neurosci. 2010;32(2): 298-309.

23. Mannara F, Radosevic M, Planagumà J, et al. Allosteric modulation of NMDA receptors prevents the antibody effects of patients with anti-NMDAR encephalitis. Brain. 2020;143(9):2709-2720.

24. Braniste V, Al-Asmakh M, Kowal C, et al. The gut microbiota influences blood-brain barrier permeability in mice. Sci Transl Med. 2014;6(263):263ra158.

25. Hill JM, Lim MA, Stone MM. Developmental milestones in the newborn mouse. In: Gozes I, editor. Neuromethods: Humana Press; 2008:131-149.

26. Simister NE, Rees AR. Isolation and characterization of an $\mathrm{Fc}$ receptor from neonatal rat small intestine. Eur J Immunol. 1985;15(7):733-738.

27. Jones EA, Waldmann TA. The mechanism of intestinal uptake and transcellular transport of IgG in the neonatal rat. J Clin Invest. 1972;51(11):2916-2927.

28. Rodewald R. pH-dependent binding of immunoglobulins to intestinal cells of the neonatal rat. J Cell Biol. 1976;71(2):666-669.

29. Simister NE, Story CM, Chen HL, Hunt JS. An IgG-transporting Fc receptor expressed in the syncytiotrophoblast of human placenta. Eur J Immunol. 1996;26(7): 1527-1531.

30. Zhang Y, Pardridge WM. Mediated efflux of IgG molecules from brain to blood across the blood-brain barrier. J Neuroimmunol. 2001;114(1-2):168-172.

31. Petkova SB, Akilesh S, Sproule TJ, et al. Enhanced half-life of genetically engineered human IgG1 antibodies in a humanized FcRn mouse model: potential application in humorally mediated autoimmune disease. Int Immunol. 2006;18(12): 1759-1769.
32. Kasprick A, Hofrichter M, Smith B, et al. Treatment with anti-neonatal Fc receptor $(\mathrm{FcRn})$ antibody ameliorates experimental epidermolysis bullosa acquisita in mice. $\mathrm{Br}$ J Pharmacol. 2020;177(10):2381-2392.

33. Roy S, Nanovskaya T, Patrikeeva S, et al. M281, an anti-FcRn antibody, inhibits IgG transfer in a human ex vivo placental perfusion model. Am J Obstet Gynecol. 2019; 220(5):498.e1-498.e9.

34. Cooper PR, Ciambrone GJ, Kliwinski CM, et al. Efflux of monoclonal antibodies from rat brain by neonatal Fc receptor. Fcrn Brain Res. 2013;1534:13-21.

35. Momenta Pharmaceuticals Inc. A Study to Test Efficacy and Safety of Rozanolixizumab in Adult Patients with Generalized Myasthenia Gravis [Internet]; 2019. Available at: clinicaltrials.gov/ct2/show/NCT03971422 (accessed January 25, 2021).

36. Momenta Pharmaceuticals Inc. A Study to Evaluate the Safety, Tolerability, Efficacy, Pharmacokinetics and Pharmacodynamics of M281 Administered to Adults with Generalized Myasthenia Gravis [Internet]; 2018. Available at: clinicaltrials.gov/ct2/show/ NCT03772587?term=M281\&rank=5 (accessed January 25, 2021).

37. Ling LE, Hillson JL, Tiessen RG, et al. M281, an anti-FcRn antibody: pharmacodynamics, pharmacokinetics, and safety across the full range of IgG reduction in a firstin-human study. Clin Pharmacol Ther. 2018;105(4):1031-1039.

38. Momenta Pharmaceuticals Inc. A Study to Evaluate the Safety, Efficacy, Pharmacokinetics and Pharmacodynamics of M281 Administered to Pregnant Women at High Risk for Early Onset Severe Hemolytic Disease of the Fetus and Newborn (HDFN) [Internet]; 2019. Available at: clinicaltrials.gov/ct2/show/NCT03842189? term $=$ M281\&rank=2 (accessed January 25, 2021).

39. Sheikhbahaei S, Sherkat R, Camacho-Ordonez N, et al. Pregnancy, child bearing and prevention of giving birth to the affected children in patients with primary immunodeficiency disease; A case-series. BMC Pregnancy Childbirth. 2018;18(1):299.

40. Mandal PK, Dolai TK, Bagchi B, et al. B cell suppression in newborn following treatment of pregnant diffuse large B-cell lymphoma patient with rituximab containing regimen. Indian J Pediatr. 2014;81(10):1092-1094. 


\title{
Neurology \\ Neuroimmunology \& Neuroinflammation
}

\author{
Blocking Placental Class G Immunoglobulin Transfer Prevents NMDA Receptor \\ Antibody Effects in Newborn Mice \\ Anna García-Serra, Marija Radosevic, José Ríos, et al. \\ Neurol Neuroimmunol Neuroinflamm 2021;8; \\ DOI 10.1212/NXI.0000000000001061
}

This information is current as of September 27, 2021

Updated Information \&

Services

References

Subspecialty Collections

Permissions \& Licensing

Reprints including high resolution figures, can be found at:

http://nn.neurology.org/content/8/6/e1061.full.html

This article cites 36 articles, 8 of which you can access for free at: http://nn.neurology.org/content/8/6/e1061.full.html\#\#ref-list-1

This article, along with others on similar topics, appears in the following collection(s):

Autoimmune diseases

http://nn.neurology.org//cgi/collection/autoimmune_diseases

Neonatal

http://nn.neurology.org//cgi/collection/neonatal

Information about reproducing this article in parts (figures,tables) or in its entirety can be found online at:

http://nn.neurology.org/misc/about.xhtml\#permissions

Information about ordering reprints can be found online:

http://nn.neurology.org/misc/addir.xhtml\#reprintsus

Neurol Neuroimmunol Neuroinflamm is an official journal of the American Academy of Neurology.

Published since April 2014, it is an open-access, online-only, continuous publication journal. Copyright

Copyright (C) 2021 The Author(s). Published by Wolters Kluwer Health, Inc. on behalf of the American

Academy of Neurology.. All rights reserved. Online ISSN: 2332-7812.

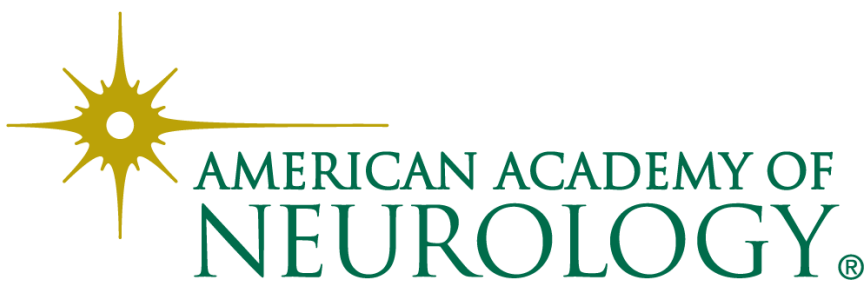

